\title{
PERSPECTIVE
}

GLOBAL HEALTH

\section{Eradicating Polio}

David L. Heymann, M.D., and R. Bruce Aylward, M.D.

During the past 12 months, poliovirus has been spreading to states in Nigeria that were previously free of poliomyelitis. Moreover, global surveillance for acute flaccid paralysis ${ }^{1}$ - involving the genomic sequencing of each wild poliovirus that is detected - has demonstrated that wild poliovirus genetically linked to parent viruses in northern Nigeria has spread to 12 other previously polio-free countries in sub-Saharan Africa.

Rumors of "contaminated" polio vaccine ignited a controversy in Kano State, in northern Nigeria, in mid-2003 and led to the immediate and official suspension of immunization activities. Such rumors the substance of which varies from the contamination of polio vaccine with human immunodeficiency virus at the time of manufacture to the deliberate addition of hormones to permanently sterilize young girls - have plagued the poliomyelitis-eradication initiative since its beginning in $1988 .^{2}$ Shortly after the suspension of polio-vaccination activities in $\mathrm{Ni}$ geria, a national commission was set up by the Federal Ministry of Health to evaluate the safety of the polio vaccines that were being used, and two different state-level commissions were established in Kano to do the same. By July 31, 2004, all three commissions had independently concluded that the polio vaccines were safe, and the governor of Kano relaunched the vaccination effort.

All countries where poliovirus is endemic procure polio vaccine through the United Nations Children's Fund (UNICEF), one of the four partners spearheading the eradication effort, along with the World Health Organization (WHO), Rotary International, and the Centers for Disease Control and Prevention. These vaccines, purchased from manufacturers that are prequalified by the $\mathrm{WHO}$, have been used safely since well before the polio-eradication initiative began in 1988. Their use has resulted in a decrease of more than 99 percent in the incidence of paralytic poliomyelitis in children, from an estimated 1000 cases per day worldwide in 1988 to fewer than 3 cases per day in 2003, with a corre- sponding decrease in the number of countries where poliovirus is endemic, from 125 to 6 (see Figure). Some children have received more than 10 doses of oral poliovirus vaccine during consecutive "national immunization day" campaigns, with no increase in the incidence of adverse events, including vaccine-associated paralytic polio, which has an estimated incidence of 2 to 4 cases per million births per year. $^{3}$

As a result of the suspension of polio-vaccination activities in Kano, between January 1 and September 1, 2004, infection with wild poliovirus has been confirmed in 491 paralyzed children in Nigeria. This country now accounts for nearly 80 percent of the global burden of paralytic poliomyelitis. In 2003 , the global surveillance system for acute flaccid paralysis identified a wild poliovirus linked to Nigeria in a child from Ghana, a country that had been free of poliomyelitis since November 2000. Since then, wild poliovirus has spread both within Nigeria, to infect persons in 31 of its 37 states, and across international borders to a total of 12 countries in sub-Saharan Africa that had been polio-free (see Figure). In many of these countries, the virus spread rapidly because, in all but two of them, the rate of polio-vaccination coverage (the percentage of children who had received at least three doses of oral poliovirus vaccine through routine immunization services) was estimated to be less than 75 percent (median, 48 percent); the exceptions were Ghana and Botswana, where the coverage rate was greater than 90 percent.

In January 2004, the ministers of health of the six remaining countries where poliovirus is endemic met in Geneva with the four spearheading organizations involved in the international polio-eradication effort and declared that they would interrupt the transmission of wild poliovirus by the end of 2004. ${ }^{4}$ India, Pakistan, Afghanistan, and Egypt - four of the six - have made great progress since then: between January 1 and September 1 , the incidence of poliomyelitis has dropped to its lowest level ever in 


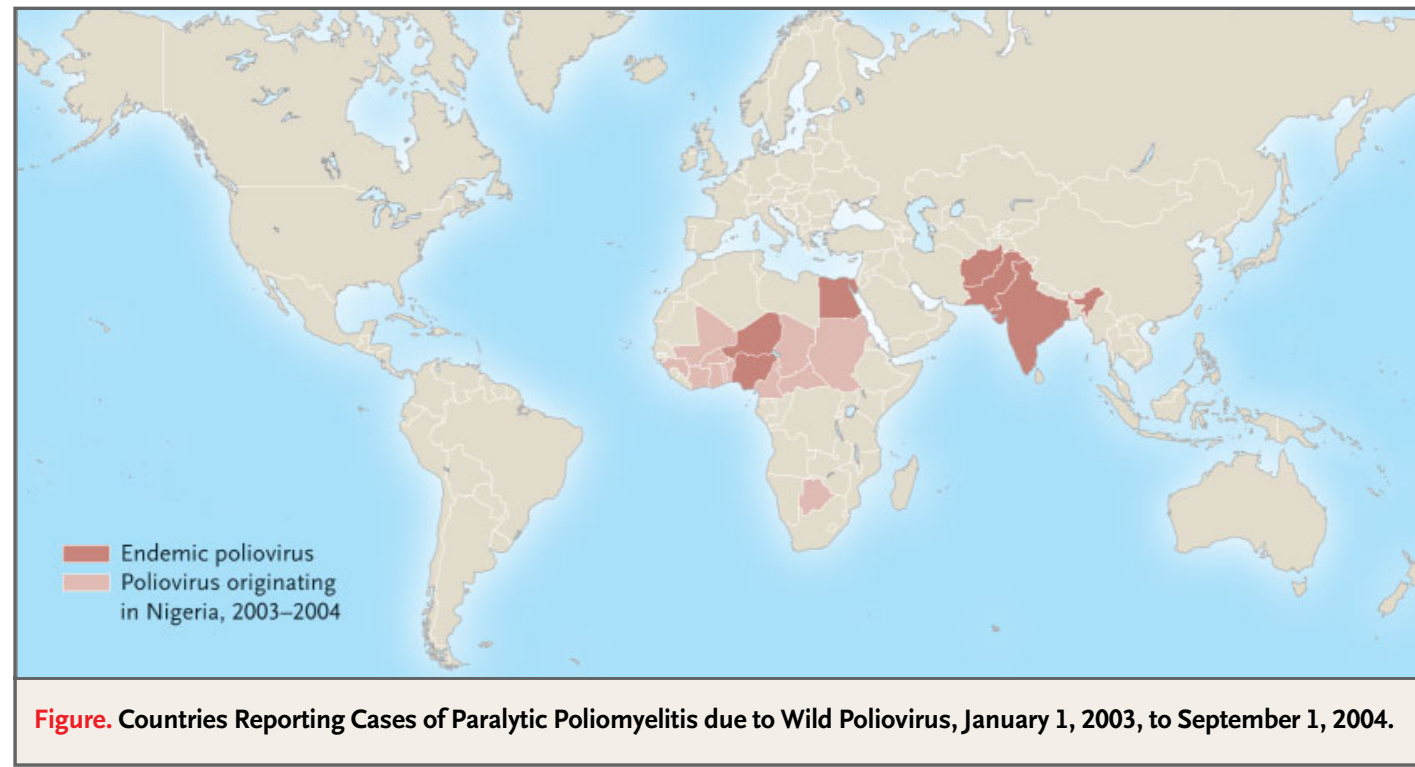

each of these countries, which together now account for 11 percent of the global burden of the disease. The current risks in these countries are those associated with a premature decrease in the intensity of both surveillance and massive, houseto-house polio "mop-up" vaccination activities in the few remaining areas where wild poliovirus has been detected.

In the two other countries where poliovirus is endemic, Niger and Nigeria, there is a danger that efforts will fail to reach more than 90 percent of the target population with effective vaccine or that the necessary financial resources will be lacking. An additional risk is that efforts to reestablish polio-free status in the 12 countries to which the virus has spread will fail. Each July, when the rainy season begins in western and central Africa, the intensity of transmission of poliovirus increases. With levels of vaccination coverage well below 50 percent in many of these countries, the task ahead is substantial. Five times as many children have been paralyzed by infection with wild poliovirus in Africa since January 1,2004 , as during the corresponding period in 2003, putting sub-Saharan Africa on the verge of the largest polio epidemic in recent history.

Planning is therefore under way in 23 western and central African countries for synchronized national immunization days in October and November 2004 and again in early 2005 to interrupt the transmission of wild poliovirus in Africa. The final eradication of polio hinges on continued government commitment in those countries where polio- virus is endemic and those that are at risk for importation, as well as on the availability of an additional $\$ 200$ million in financial resources for the vaccination activities required to do the job.

If the campaign is successful and the international spread of wild poliovirus is contained, at least one further step will be required to eliminate polio: all countries that are now using oral poliovirus vaccine must cease using it after global eradication, in order to eliminate the risks of paralytic poliomyelitis from vaccine-associated paralytic polio and circulating vaccine-derived poliovirus. ${ }^{5}$ First identified in 1999 in Hispaniola and then found in the Philippines, in Madagascar, and retrospectively in Egypt, circulating vaccine-derived poliovirus is now known to be another challenge to polio eradication, especially where routine immunization coverage is low and surveillance for acute flaccid paralysis weak, because of its capacity to cause outbreaks of paralytic disease. After transmission of wild poliovirus has been interrupted, such vaccine-derived virus will therefore be a source of paralytic disease, and this risk of transmission will continue as long as the oral poliovirus vaccine remains in use. ${ }^{5}$

Other long-term, albeit small, risks include the potential reintroduction into the community of a vaccine-derived poliovirus from prolonged excretion by a person with a severe primary immunodeficiency syndrome and the reintroduction of a wild or Sabin poliovirus from a laboratory or vaccine-production facility. With the current knowledge about these risks, the continued global surveillance for po- 
liovirus, and the availability of a vaccine stockpile in case of an outbreak, however, countries are increasingly equipped to decide on the most appropriate vaccination policies after the eradication of polio.

From the Polio Eradication Initiative, World Health Organization, Geneva.

1. Expanded Programme on Immunization. Field guide for supplemental activities aimed at achieving polio eradication. Geneva: World Health Organization, 1995. (WHO/EPI/GEN/95.6.)
2. Plotkin S. CHAT oral polio vaccine was not the source of human immunodeficiency virus type 1 group $M$ for humans. Clin Infect Dis 2001;32:1068-84.

3. Introduction of inactivated poliovirus vaccine into oral poliovirus vaccine-using countries. Wkly Epidemiol Rec 2003;78:24152.

4. Geneva declaration for the eradication of poliomyelitis. Geneva: World Health Organization, January 2004.

5. Report of the WHO Consultation on Identification and Management of Vaccine-derived Polioviruses. Geneva: World Health Organization (in press).

\title{
Back to the '90s - The Supreme Court Immunizes Managed Care
}

\author{
M. Gregg Bloche, M.D., J.D.
}

Should the law let patients sue health plans for damages when plans deny coverage and bad results ensue? A June ruling by the U.S. Supreme Court has returned this question to the forefront of the nation's political agenda. The decision, in Aetna v. Davi$l a,{ }^{1}$ immunized employer-sponsored health plans against damage suits for wrongful denial of coverage. It voided statutes in 10 states that expressly allowed such suits and barred courts everywhere from permitting such claims to go forward under judgemade law. Consumer advocates, congressional Democrats, and their party's presidential nominee, John Kerry, vowed legislative action to end managed care's immunity, setting up a struggle with the Bush administration, which backed the industry in Aetna v. Davila. What does this mean for patients and physicians?

Americans with private health insurance typically obtain their coverage through the workplace, under the terms of a convoluted federal statute that was not designed with medical care in mind. Congress passed this law, known as the Employee Retirement Income Security Act (ERISA), in 1974 to protect workers' retirement income in the wake of a series of pension-fund scandals that were the Enron and WorldCom affairs of their day. Because ERISA supplanted wide areas of state law, it nullified most rules governing workplace-based health insurance.

The rise of managed care in the 1980s exposed this regulatory void, as aggrieved patients sought remedies and found that they had none. By the mid1990 s, the conventional wisdom, supported by sev- eral court rulings, ${ }^{2}$ held that managed-care health plans could not be sued for withholding coverage or care. The public's ire over insurers' impunity helped to fuel the late-1990s backlash against managed care. Market pressures and the prospect of a "Patients' Bill of Rights" pushed health plans away from intrusive cost-control methods, including the refusal to cover medically prescribed treatments. ${ }^{3}$

Interest-group gridlock stymied congressional efforts to enact a "Patients' Bill of Rights," but federal judges began to reinterpret ERISA in such a way as to shrink the legal void. In the late 1990s, lower courts allowed patients to sue health plans for malpractice committed by plan physicians, and in 2002, the Supreme Court upheld laws in more than 40 states mandating independent medical review when plans deny coverage. ${ }^{4}$ Since 2000 , a number of lower courts have permitted damage suits against plans for withholding care. When the Supreme Court agreed to consider Aetna v. Davila, many observers expected the justices to craft an obituary for managed care's immunity from such claims.

Instead, the Court fully restored this immunity, striking down a Texas law authorizing such suits. As a candidate for president four years ago, former Texas governor George Bush pointed to this law, passed on his watch, as proof of his commitment to patients' rights. But last December, the Bush administration asked the justices to reject the law, warning that it and similar laws in other states would push health care costs skyward.

The evidence, however, suggests that empowering patients to seek damages for coverage denied 